\title{
Health and nutrition education in primary schools of Crete: changes in chronic disease risk factors following a 6-year intervention programme
}

\author{
Yannis Manios, Joanna Moschandreas, Christos Hatzis and Anthony Kafatos* \\ Preventive Medicine and Nutrition Clinic, School of Medicine, University of Crete, PO Box 1393, Iraklio, Crete, Greece
}

(Received 21 May 2001 - Revised 12 March 2002 - Accepted 11 April 2002)

\begin{abstract}
The effectiveness of a health and nutrition education programme, in changing certain chronic disease risk factors, was assessed after the 6 years intervention period was completed. The school-based intervention programme was applied to all children registered in the first grade (age 5.5-6.5 years) in 1992 in two counties of Crete, while the children from a third county served as a control group. In order to assess the effectiveness of the intervention, a variety of biological and behavioural parameters were measured before and following completion of the intervention in a randomly selected school-based sample of 602 intervention group (IG) and 444 control group (CG) pupils. At the end of the 6-year period, it was found that biochemical indices generally improved significantly more in the IG compared with the CG (mean change for IG $v$. CG was $-0.27 v$. $-0.12 \mathrm{mmol} / \mathrm{l}$ for total cholesterol (TC); $-0.07 v .+0 \cdot 24$ for TC:HDL and $-0.13 v .+0.14$ for LDL:HDL). Similarly, the changes observed in the anthropometric variables in the two groups were in favour of the IG $\left(+3.68 v .+4.28 \mathrm{~kg} / \mathrm{m}^{2}\right.$ for BMI; $+2.97 v .+4.47 \mathrm{~mm}$ for biceps skinfold). Total energy intake and consumption of total fat and saturated fat increased significantly less in the IG compared with the CG $(+747.7 v .1534 .7 \mathrm{~kJ}(+178.7 v .+366.8 \mathrm{kcal}) ;+5.9 v .+18.8 \mathrm{~g}$ and $+0.8 v .+5.1 \mathrm{~g}$ respectively), while time devoted to leisure time physical activity and cardiovascular run test performance increased significantly more in the IG $(+281 v$. $+174 \mathrm{~min} /$ week and $+2.5 v \cdot+1.2$ stages respectively). The findings of the present study underline the importance of such programmes in health promotion and disease prevention. Although the long-term effects of these programmes can only be assessed by tracking this population through to adolescence and adulthood, these programmes seem to have the potential to lead to a healthier lifestyle and thus a reduction in risk factor levels.
\end{abstract}

Nutrition education: Children: Cardiovascular risk factors: Diet and exercise

Health and nutrition education in Greece has only recently begun to be seriously considered as one of the most promising solutions for health promotion and reduction of morbidity and mortality in the Greek population. The need for comprehensive, longitudinal, health education programmes is increasingly obvious in view of the rising rates of morbidity and mortality in the Greek adult population caused by chronic diseases associated with contemporary lifestyles and nutritional habits which involve lack of significant exercise, unsatisfactory nutritional habits and smoking (Kafatos et al. 1991; Voukiklaris et al. 1996; Kafatos \& Papoutsakis, 1998). The major risk factors leading to CHD have their roots in childhood (Wynder et al. 1981). Epidemiological studies in Greece during the last 30 years have indicated a high prevalence of CHD risk factors and other chronic disease risk factors (such as obesity, hypertension, hypercholesterolaemia, active and passive smoking and low levels of physical activity) in children and adolescents (Kafatos et al. 1981; Fordyce et al. 1983; Aravanis et al. 1988; Manios et al. 1999a). The main reasons for these negative indices are, apart from a limited awareness of health and dietary issues, poor dietary habits and the sedentary lifestyles of contemporary Greeks (Kafatos \& Mamalakis, 1993; Kafatos et al. 1999).

Despite the high prevalence of risk factors, and the positive results of a few small-scale initiatives (Lionis et al. 1991; Kafatos \& Mamalakis, 1993) no national policy exists to date in Greece on health education in schools as a means of combating the expected rising rates of morbidity and mortality from chronic diseases. A health, nutrition

\footnotetext{
Abbreviations: CG, control group; IG, intervention group; MVPA, moderate-to-vigorous physical exercise; PE, physical education; TC, total cholesterol; TG, triacylglycerol.

* Corresponding author: Professor A. Kafatos, fax +30 81394 604, email: manios@ hua.gr
} 
and physical exercise education programme was launched in 1992 in Crete by the Department of Social Medicine of the University of Crete. The intervention programme, which had a projected duration of 6 years, was initiated and developed in order to foster healthy dietary and general lifestyle habits in children, with the ultimate aim of promoting health and minimising risk factors for the development of chronic diseases. This programme represents one of the longest running attempts in Greece to obtain adequate epidemiological data and test the effectiveness of a health education intervention applied in primary schools. The design, implementation and preliminary outcomes of the first 3 years of intervention have been published elsewhere (Manios et al. 1998a, 1999b). In the present paper outcomes relating to health indices over the 6 years of intervention in primary schools are presented.

\section{Subjects and methods}

According to the 1991 National Records (GNSC, 1995), the population of the three main counties of the Island of Crete is homogeneous, consisting of more than $99 \%$ Christian Orthodox Greek citizens sharing the same customs and traditions. At a county level, no differences exist regarding education (the percentages of population having a university degree varies between 5.6 and $6.0 \%$ in the three counties), income (annual income per capita varies between $€ 3664$ and $€ 3857$ in the three counties) and unemployment (varies between 5.9 and $6.2 \%$ in each county). However, some differences do exist regarding levels of education, socio-economic status and lifestyle between the urban coastal areas, which are more touristic and economically developed and the mountainous, rural areas, which are less economically developed and the main income is from agriculture. The urban population is concentrated in three towns, one in each county, with 45000 inhabitants in the town of Rethimno (the capital in the county of Rethimno), 73000 inhabitants in the town of Hania (the capital in the county of Hania) and 152000 inhabitants in the town of Iraklio (the capital in the county of Iraklio). The rural population is spread on the mountainous areas in small villages with less than 4000 inhabitants each. In all three counties the population is distributed by about $45 \%$ in the rural areas and $55 \%$ in the urban areas making the distribution of the population fairly homogeneous among the three counties. Since no differences exist at a county level, the selection of the intervention and control counties was based on practical issues such as the distance of the selected schools from the university campus where the Preventive Medicine and Nutrition Clinic was based. The same strategy for optimising practical issues has been used in other studies too (Jacobs et al. 1986). The present study was therefore not randomised at a county level but rather the study design was such as to maximize the effectiveness of monitoring the implementation of the intervention programme, as in the county of Hania the average distance between the university campus and the selected schools is $160 \mathrm{~km}$.

The health education intervention programme was initiated in September 1992 with the approval of the Greek Ministry of Education. The population of the intervention group (IG) was comprised, in total, of the 4171 children registered in the first grade (age 5.5-6.5 years) of primary schools throughout the counties of Iraklio and Rethimno in September 1992 while the 1510 children registered in the county of Hania served as the control group (CG). A random sample of twenty-four schools (602 pupils) in the intervention counties of Iraklio and Rethimno were selected in order to assess the effectiveness of the programme. Similarly, sixteen schools (444 pupils) in the county of Hania, having no health and nutrition intervention, were randomly selected for comparative evaluation purposes. Reflecting the geographical distribution of the population, $49.8 \%$ of these pupils came from urban areas and $50.2 \%$ came from rural areas.

Between September and October 1992, before commencement of the educational intervention, a full medical examination took place of all the children in the first grade at the randomly selected schools. An interim evaluation was conducted when the children were in the fourth grade (age 8.5-9.5 years) (Manios et al. 1999b) while the final examination of these children took place when they were in the sixth grade (age 10.5-11.5 years) and the 6-year intervention programme had been completed. The final examination was conducted during the period between May and June 1998. Before commencement of the study, each family was informed in writing about the nature of the programme and written consent was obtained for the children in the sampled schools.

During the evaluation periods, a maximum of thirty pupils and their parents were screened each day by a team of trained personnel. The data collected from the children (in both IG and CG) were health knowledge scores, dietary and exercising habits, anthropometric measurements, physical fitness indices and biochemical examinations. A multiple-choice questionnaire with colour illustrations was used to assess pupils' knowledge on health issues at the beginning and at the end of the 6-year intervention period. The questionnaire focused on diet, food products and advertising, physical activity, smoking hazards and accident prevention (Manios et al. 1999b).

Parents provided feedback during the study in two main ways: (a) by completing coded questionnaires regarding personal characteristics (age, occupation, years of education etc.) and issues related to their own and their children's health habits and knowledge; (b) by completing questionnaires regarding their children's dietary habits and leisure time physical activity and times of inactivity.

Parents completed a questionnaire regarding their children's weekly food frequency consumption of various foods and, in a random sample of $30 \%$ of the baseline cohort, by providing a weighed record of all foods consumed by their child over a $3 \mathrm{~d}$ period. Parents were given oral and written instructions for correct completion of forms. Implementation of the procedure was closely monitored by dietitians (Manios et al. 1999b). The dietary data presented in the present paper are from the $3 \mathrm{~d}$ weighed food record. The foods were coded and analysed using the University of Crete's computerised 'Greek Diet' food database that is based on the USDA database (USDA, 2001) but has been extensively amended to include chemically analysed Greek foods. Fat analysis, 
including monounsaturated fatty acids, polyunsaturated fatty acids and saturated fatty acids, was based on the chemical analysis of over 100 Greek foods providing $95 \%$ of the fat in the Greek diet (undertaken during the TRANSFAIR programme, in which the University of Crete participated). Chemical analysis was undertaken by the Wageningen Agricultural University and TNO Voeding in the Netherlands.

Assessment of moderate-to-vigorous physical activity (MVPA) out of school was performed using a standardised activity interview based on a questionnaire completed by the grade six children in the presence of a member of the research team. The same questionnaire was completed by the parents when children were at the first grade. Further details regarding the reliability and validity of the questionnaire are given elsewhere (Manios et al. 1998b). Pre- and post-intervention evaluations of physical fitness were based on the EUROFIT Tests Protocol designed by the Committee of Experts on Sports Research (Committee of Experts on Sports Research, 1988). The battery of tests included:

1. Sit and reach test: reaching as far as possible from a sitting position.

2. Sit-ups: maximum number of sit-ups achieved in $30 \mathrm{~s}$.

3. Handgrip test: squeezing a calibrated hand dynamometer as forcefully as possible with the dominant hand.

4. Standing broad jump test: jumping for a distance from a standing start.

5. Endurance $20 \mathrm{~m}$ shuttle run test: this is a standard test of cardiovascular fitness in school children.

Body weight was measured by a digital scale (Seca) with an accuracy of $\pm 100 \mathrm{~g}$. Subjects were weighed without shoes, in their underwear. Standing height was measured without shoes to the nearest $5 \mathrm{~mm}$ with the use of a commercial stadiometer with the shoulders in relaxed position and arms hanging freely. BMI was calculated by dividing weight $(\mathrm{kg})$ by height squared $\left(\mathrm{m}^{2}\right)$. Left triceps, biceps, subscapular and supra-iliac skinfold thickness were measured with a Lange skinfold calliper, ensuring that the subject was standing with the upper extremities relaxed at the sides of the body (Manios et al. 1998a, 1999b).

Early morning venous blood samples were taken from each child for biochemical screening tests, following a $12 \mathrm{~h}$ overnight fast. One portion was used for blood analysis of triacylglycerols (TG), total cholesterol (TC) and HDL-cholesterol measurements on the same day of collection. LDL-cholesterol was calculated as follows: LDLcholesterol $=$ TC - HDL-cholesterol - TG/5 (Friedewald et al. 1972).

The intervention programme used in the present study was based on the health profile component of the 'Know Your Body' school health promotion programme of the American Health Foundation (Williams et al. 1977; Walter \& Wynder, 1989), which was adapted, modified and supplemented to suit our population. Multi-component workbooks covering mainly dietary issues, physical activity and fitness, but also dental health hygiene, drug abuse and accident prevention were produced for grades 1-6 with each pupil being supplied a workbook per year. Additionally, teaching aids, produced by the researchers, in the form of teaching manuals, audio-taped fairytales, posters and workbooks were provided. The nutrition components of the programme were conducted by the class teacher and incorporated $13-17 \mathrm{~h}$ of classroom material annually. The physical fitness and activity component of the programme had a practical and a theoretical part (4$6 \mathrm{~h}$ of classroom material per year), and both were delivered by physical education (PE) instructors during the two 45 min of PE classes per week. Details regarding the theoretical framework on which the design and implementation of the intervention was based on are presented elsewhere (Manios et al. 1999b).

The statistical analyses performed were mixed model analyses, based on the changes observed before and after the intervention programme, in the IG and the CG. Changes were estimated in the measured variables in the two groups over the 6-year intervention period, taking account of possible inter-school variation by including the random school effect in the model. Adjustments were made for baseline values, sex, parental education levels, increase in height and initial BMI (in the models for the biochemical, anthropometric and physical activity data). For the nutrient data, the estimated changes were adjusted for baseline values, sex and BMI. SPSS version 7.5 was used in the general linear model (GLM) analyses. Further details with regard to the statistical modelling approach used to assess intervention effects are provided elsewhere (Manios et al. 1999b). Baseline measurements in pupils completing the health intervention programme were compared with the measurements for those not completing the programme using the non-parametric univariate Mann-Whitney test.

\section{Results}

In Table 1 it can be seen that of the 1046 pupils initially in the intervention programme, 831 were available at the final assessment stage. Of the 215 children who did not complete the programme, $164(76 \%)$ of these were not re-examined because they changed schools during the 6year period. For the remaining fifty-one children (24\%), the losses-to-follow-up by county were $25 \%$ in Iraklio, $14 \%$ in Rethimno and $23 \%$ in Hania. The pupils included in the estimation of intervention effects were those pupils measured both at baseline and after 6 years who did not change schools during the intervention period (787 pupils). Only those pupils with complete records for each component were included in the multivariable analyses presented in Tables 2-5.

Table 1 shows that the mean values of the main measurements for the 6-year-old pupils followed up to full-term did not differ in the main from those not examined at full-term. There is some evidence that LDL concentrations at baseline were higher for those not completing the programme (mean 3.04 (SD 0.67) v. 2.91 (SD 0.75) $\mathrm{mmol} / \mathrm{l}, P<0.05)$ and the baseline serum TG concentrations were lower in those not completing the programme (mean 0.63 (SD 0.28) v. 0.69 (SD 0.30) mmol/1, $P<0.001)$. When pupils re-examined in $1998 v$. those not re-examined were treated separately for IG and CG, no significant differences were found in baseline data between pupils 
Table 1. Comparison of baseline measurements for pupils not completing the programme with those with full 6-year participation*

(Mean values with their standard deviations)

\begin{tabular}{|c|c|c|c|c|c|}
\hline \multirow{2}{*}{$\begin{array}{l}\text { Serum lipid measurements } \\
\text { and anthropometric indices }\end{array}$} & \multicolumn{2}{|c|}{$\begin{array}{l}\text { Pupils not completing } \\
\text { the programme } \\
(n 215) \dagger\end{array}$} & \multicolumn{2}{|c|}{$\begin{array}{l}\text { Pupils with complete } \\
\text { participation } \\
(n \text { 831)‡ }\end{array}$} & \multirow[b]{2}{*}{$P$ values $\S$} \\
\hline & Mean & SD & Mean & SD & \\
\hline Cholesterol (mmol/l) & 4.85 & 0.71 & 4.74 & 0.81 & $<0.05$ \\
\hline Triacylglycerols (mmol/l) & 0.63 & 0.28 & 0.69 & 0.30 & $<0.001$ \\
\hline LDL $(\mathrm{mmol} / \mathrm{l})$ & 3.04 & 0.67 & $2 \cdot 91$ & 0.75 & $<0.05$ \\
\hline $\mathrm{HDL}(\mathrm{mmol} / \mathrm{l})$ & 1.50 & 0.35 & 1.54 & 0.35 & NS \\
\hline Weight (kg) & 23.7 & $5 \cdot 1$ & $23 \cdot 6$ & 4.7 & NS \\
\hline Height (cm) & $120 \cdot 0$ & $6 \cdot 1$ & $120 \cdot 1$ & $5 \cdot 7$ & NS \\
\hline BMI $\left(\mathrm{kg} / \mathrm{m}^{2}\right)$ & $16 \cdot 3$ & 2.5 & $16 \cdot 3$ & $2 \cdot 3$ & NS \\
\hline Waist:hip & 0.86 & 0.05 & 0.86 & 0.05 & NS \\
\hline
\end{tabular}

${ }^{*}$ For details of subjects and procedures, see p. 316.

† Of the 215 pupils not completing the programme, 119 pupils $(55 \%)$ were males, ninety-six pupils (45\%) were females; 144 $(67 \%)$ were allocated to the intervention group, seventy-one $(33 \%)$ were controls of the non-completers, $179(83 \%)$ had biochemical measurements and $168(78 \%)$ had anthropometric measurements.

$\ddagger$ Of the 831 who completed the programme, 427 pupils (51\%) were males, 404 pupils (49\%) were females, 457 (55\%) were intervention group pupils, $374(45 \%)$ were controls of the completers, $758(91 \%)$ had biochemical measurements and 721 $(87 \%)$ had anthropometric measurements.

$\S$ The levels of significance were assessed with the use of the Mann-Whitney test.

completing the 6-year programme and those not completing the programme in either group (data not shown).

There were notable differences in the extent to which the nutrient intake changed in the two groups, as can be seen in
Table 2. The increase in the average energy intake was higher in the CG (1535 (SE 241) kJ (366.8 (SE 57.5) kcal)) than the IG (748 (SE 277) $\mathrm{kJ}$ (178.7 (SE 66.1) kcal)), $P<0.05$. It can be seen that the 6-year increases

Table 2. Comparisons of changes in daily nutrient intakes between intervention ( $n 90)$ and control ( $n$ 86) groups following the 6-year intervention programme, based on weighed $3 \mathrm{~d}$ records*

(Mean values and standard deviations or standard errors)

\begin{tabular}{|c|c|c|c|c|c|c|c|}
\hline \multirow[b]{2}{*}{ Nutrient } & \multicolumn{2}{|c|}{ Baseline } & \multicolumn{2}{|c|}{ Final } & \multicolumn{2}{|c|}{ Change } & \multirow[b]{2}{*}{$P$ values } \\
\hline & Mean & SD & Mean & SD & Mean & SE & \\
\hline \multicolumn{8}{|l|}{ Energy (kJ) } \\
\hline Intervention group & $7709 \cdot 4$ & $1815 \cdot 0$ & $8332 \cdot 0$ & $2218 \cdot 8$ & $747 \cdot 7$ & $276 \cdot 6$ & \multirow[t]{2}{*}{$<0.05$} \\
\hline Control group & $7718 \cdot 6$ & $1832 \cdot 2$ & $9162 \cdot 1$ & 2174.4 & $1534 \cdot 7$ & $240 \cdot 6$ & \\
\hline \multicolumn{8}{|l|}{ Total fat $(\mathrm{g})$} \\
\hline Intervention group & $87 \cdot 0$ & 23.9 & $92 \cdot 0$ & $30 \cdot 5$ & 5.9 & $4 \cdot 1$ & \multirow[t]{2}{*}{$<0.05$} \\
\hline Control group & $86 \cdot 8$ & $25 \cdot 0$ & 103.9 & 31.7 & $18 \cdot 8$ & 3.5 & \\
\hline \multicolumn{8}{|c|}{ Monounsaturated fatty acids (g) } \\
\hline Intervention group & $36 \cdot 2$ & 11.6 & $39 \cdot 1$ & $15 \cdot 3$ & $2 \cdot 7$ & $2 \cdot 0$ & \multirow[t]{2}{*}{$<0.05$} \\
\hline Control group & $36 . \overline{9}$ & $12 \cdot 6$ & $44 \cdot 2$ & $16 \cdot 1$ & $8 \cdot 7$ & $1 \cdot 8$ & \\
\hline \multicolumn{8}{|c|}{ Polyunsaturated fatty acids (g) } \\
\hline Intervention group & 9.7 & 3.3 & $10 \cdot 8$ & $4 \cdot 2$ & 1.0 & 0.6 & \multirow[t]{2}{*}{ NS } \\
\hline Control group & $9 \cdot 4$ & $3 \cdot 0$ & 11.3 & 4.3 & $2 \cdot 0$ & 0.5 & \\
\hline \multicolumn{8}{|l|}{ Saturated fatty acids (g) } \\
\hline Intervention group & $31 \cdot 2$ & $9 \cdot 1$ & $31 \cdot 3$ & $10 \cdot 3$ & 0.8 & 1.4 & \multirow[t]{2}{*}{$<0.05$} \\
\hline Control group & 30.6 & $9 \cdot 1$ & 35.6 & $10 \cdot 9$ & 5.1 & 1.2 & \\
\hline \multicolumn{8}{|l|}{ Trans-fatty acids (g) } \\
\hline Intervention group & 1.5 & 0.8 & $2 \cdot 1$ & 1.4 & 0.8 & 0.2 & \multirow[t]{2}{*}{ NS } \\
\hline Control group & 1.6 & 0.9 & $2 \cdot 1$ & $1 \cdot 2$ & 0.7 & 0.1 & \\
\hline \multicolumn{8}{|l|}{ Protein $(\mathrm{g})$} \\
\hline Intervention group & $62 \cdot 9$ & $17 \cdot 8$ & $70 \cdot 7$ & $21 \cdot 4$ & 11.3 & $2 \cdot 8$ & \multirow[t]{2}{*}{$<0.05$} \\
\hline Control group & $63 \cdot 4$ & $17 \cdot 8$ & $79 \cdot 7$ & $21 \cdot 7$ & $16 \cdot 9$ & $2 \cdot 4$ & \\
\hline \multicolumn{8}{|l|}{ Carbohydrate (g) } \\
\hline Intervention group & 203.9 & $57 \cdot 6$ & 224.9 & $66 \cdot 0$ & 23.4 & $7 \cdot 8$ & \multirow[t]{2}{*}{ NS } \\
\hline Control group & $202 \cdot 0$ & 52.0 & 239.5 & $59 \cdot 2$ & 37.7 & 6.9 & \\
\hline \multicolumn{8}{|l|}{ Fibre $(\mathrm{g})$} \\
\hline Intervention group & $14 \cdot 2$ & $5 \cdot 3$ & 14.9 & $6 \cdot 1$ & 0.7 & 0.8 & \multirow[t]{2}{*}{ NS } \\
\hline Control group & $14 \cdot 1$ & $5 \cdot 4$ & $16 \cdot 8$ & $6 \cdot 0$ & $3 \cdot 2$ & 0.7 & \\
\hline
\end{tabular}

* Nutrient intakes were assessed in a $30 \%$ subsample. The difference between the two groups was estimated with a general linear model (GLM) adjusted for baseline values, sex and BMI. School was taken as a random effect. Summaries are presented for those pupils with nutrient data in both 1992 and 1998. For details of procedures, see p. 316. 
Table 3. Comparisons of changes in fitness indices and in leisure time physical activity between intervention ( $n$ 356) and control ( $n$ 285) groups following the 6-year intervention programme*

(Mean values and standard deviations or standard errors)

\begin{tabular}{|c|c|c|c|c|c|c|c|}
\hline \multirow[b]{2}{*}{ Fitness tests } & \multicolumn{2}{|c|}{ Baseline } & \multicolumn{2}{|c|}{ Final } & \multicolumn{2}{|c|}{ Change } & \multirow[b]{2}{*}{$P$ values } \\
\hline & Mean & SD & Mean & SD & Mean & SE & \\
\hline \multicolumn{8}{|l|}{ Standing broad jump (cm) } \\
\hline Intervention group & $85 \cdot 6$ & $15 \cdot 6$ & $143 \cdot 9$ & $26 \cdot 7$ & $56 \cdot 3$ & $1 \cdot 3$ & \multirow[t]{2}{*}{ NS } \\
\hline Control group & $84 \cdot 0$ & $15 \cdot 5$ & $135 \cdot 3$ & $23 \cdot 3$ & $51 \cdot 8$ & $1 \cdot 3$ & \\
\hline \multicolumn{8}{|l|}{ Sit-ups (repetitions) } \\
\hline Intervention group & $7 \cdot 0$ & $5 \cdot 3$ & $18 \cdot 8$ & 4.6 & $11 \cdot 3$ & 0.2 & \multirow[t]{2}{*}{ NS } \\
\hline Control group & $7 \cdot 8$ & $5 \cdot 7$ & $18 \cdot 5$ & $4 \cdot 3$ & $10 \cdot 6$ & 0.2 & \\
\hline \multicolumn{8}{|l|}{ Sit and reach $(\mathrm{mm})$} \\
\hline Intervention group & 152 & 54 & 97 & 68 & -53 & 4 & \multirow[t]{2}{*}{ NS } \\
\hline Control group & 153 & 51 & 104 & 66 & -49 & 4 & \\
\hline \multicolumn{8}{|l|}{ Handgrip (kg) } \\
\hline Intervention group & $6 \cdot 8$ & $2 \cdot 6$ & $21 \cdot 1$ & 4.9 & $13 \cdot 8$ & 0.2 & \multirow[t]{2}{*}{ NS } \\
\hline Control group & 7.5 & $2 \cdot 8$ & $21 \cdot 0$ & 4.7 & $14 \cdot 0$ & 0.2 & \\
\hline \multicolumn{8}{|l|}{ Endurance run test (stages) } \\
\hline Intervention group & $1 \cdot 6$ & 0.7 & $4 \cdot 2$ & $2 \cdot 3$ & 2.5 & $0 \cdot 1$ & \multirow[t]{2}{*}{$<0.0001$} \\
\hline Control group & $1 \cdot 8$ & 0.9 & $3 \cdot 0$ & 1.5 & $1 \cdot 2$ & $0 \cdot 1$ & \\
\hline \multicolumn{8}{|c|}{ Moderate-to-vigorous physical activity (min/week) } \\
\hline Intervention group ( $n$ 287) & $55 \cdot 2$ & $116 \cdot 0$ & $338 \cdot 3$ & 361.5 & $281 \cdot 3$ & $22 \cdot 0$ & \multirow[t]{2}{*}{$<0.05$} \\
\hline Control group ( $n$ 206) & $74 \cdot 6$ & $133 \cdot 7$ & $244 \cdot 2$ & $300 \cdot 6$ & 174.5 & $25 \cdot 7$ & \\
\hline
\end{tabular}

* The difference between the two groups was estimated with a general linear model (GLM) adjusted for baseline values, sex, initial BMI, change in height and parental education. School was taken as a random effect. Summaries are presented for those pupils with fitness data in both 1992 and 1998. For details of procedures, see p. 316.

in the average absolute intakes of protein, total fat, saturated fatty acids and monounsaturated fatty acids were again significantly higher in the CG pupils, after adjustment for baseline values and BMI. Food group intake was also assessed using the following classification: dairy, meats, fish, eggs, fats and oils, grains, vegetables, fruits, sweets and sugars. The differences observed for the nutrient intakes appear to be reflected to an extent by the differences observed in the food groups intake, although the latest reached a level of statistical significance only in the case of the grains group (with $P=0.003$ and $95 \%$ CI for the difference in the change score between

Table 4. Comparisons of changes in anthropometric measurements between intervention ( $n$ 356) and control ( $n$ 285) groups following the 6-year intervention programme*

(Mean values and standard deviations or standard errors)

\begin{tabular}{|c|c|c|c|c|c|c|c|}
\hline \multirow[b]{2}{*}{ Anthropometric variable } & \multicolumn{2}{|c|}{ Baseline } & \multicolumn{2}{|c|}{ Final } & \multicolumn{2}{|c|}{ Change } & \multirow[b]{2}{*}{$P$ values } \\
\hline & Mean & SD & Mean & SD & Mean & SE & \\
\hline \multicolumn{8}{|l|}{ Weight (kg) } \\
\hline Intervention group & $23 \cdot 1$ & 4.5 & $45 \cdot 2$ & $11 \cdot 2$ & 21.6 & 0.37 & \multirow{2}{*}{$<0.05$} \\
\hline Control group & $24 \cdot 3$ & 4.6 & $46 \cdot 2$ & 11.5 & $22 \cdot 9$ & 0.38 & \\
\hline \multicolumn{8}{|l|}{ Height $(\mathrm{cm})$} \\
\hline Intervention group & $118 \cdot 7$ & 5.4 & $150 \cdot 0$ & $7 \cdot 8$ & $31 \cdot 3$ & 0.26 & \multirow[t]{2}{*}{$<0.001$} \\
\hline Control group & 121.5 & $5 \cdot 7$ & $149 \cdot 6$ & $7 \cdot 6$ & 27.4 & 0.26 & \\
\hline \multicolumn{8}{|l|}{ BMI $\left(\mathrm{kg} / \mathrm{m}^{2}\right)$} \\
\hline Intervention group & $16 \cdot 3$ & $2 \cdot 3$ & $19 \cdot 9$ & 3.9 & 3.68 & 0.16 & \multirow[t]{2}{*}{$<0.05$} \\
\hline Control group & $16 \cdot 3$ & $2 \cdot 2$ & 20.5 & 4.1 & 4.28 & 0.16 & \\
\hline \multicolumn{8}{|l|}{ Biceps skinfold (mm) } \\
\hline Intervention group & $5 \cdot 1$ & $2 \cdot 3$ & $8 \cdot 1$ & 4.2 & 2.97 & 0.24 & \multirow[t]{2}{*}{$<0.001$} \\
\hline Control group & $5 \cdot 4$ & $2 \cdot 7$ & 9.8 & $5 \cdot \overline{8}$ & 4.47 & 0.24 & \\
\hline \multicolumn{8}{|l|}{ Triceps skinfold (mm) } \\
\hline Intervention group & $10 \cdot 6$ & 4.4 & 17.5 & $7 \cdot 7$ & 6.46 & 0.38 & \multirow[t]{2}{*}{$<0.05$} \\
\hline Control group & 11.6 & 4.9 & $19 \cdot 1$ & 8.5 & 7.90 & 0.39 & \\
\hline \multicolumn{8}{|l|}{ Supra-iliac skinfold (mm) } \\
\hline Intervention group & 7.4 & 5.9 & $20 \cdot 1$ & $12 \cdot 3$ & $12 \cdot 3$ & 0.6 & \multirow[t]{2}{*}{ NS } \\
\hline Control group & $7 \cdot 3$ & $5 \cdot 7$ & $19 \cdot 4$ & $11 \cdot 3$ & $12 \cdot 8$ & 0.6 & \\
\hline \multicolumn{8}{|l|}{ Subscapular skinfold (mm) } \\
\hline Intervention group & $7 \cdot 3$ & 4.3 & 11.9 & $7 \cdot 3$ & 4.3 & 0.3 & \multirow[t]{2}{*}{ NS } \\
\hline Control group & $7 \cdot 7$ & $5 \cdot 2$ & $12 \cdot 6$ & $7 \cdot 7$ & $5 \cdot 4$ & 0.4 & \\
\hline
\end{tabular}

* The difference between the two groups was estimated with a general linear model (GLM) adjusted for baseline values, sex, initial BMI, change in height (where appropriate and parental education. School was taken as a random effect. Summaries are presented for those pupils with anthropometric data in both 1992 and 1998. For details of procedures, see p. 316. 
Table 5. Comparisons of changes in serum lipid concentrations between intervention ( $n$ 347) and control $(n 257)$ groups following the 6-year intervention programme*

(Mean values and standard deviations or standard errors)

\begin{tabular}{|c|c|c|c|c|c|c|c|}
\hline \multirow[b]{2}{*}{ Serum lipids } & \multicolumn{2}{|c|}{ Baseline } & \multicolumn{2}{|c|}{ Final } & \multicolumn{2}{|c|}{ Change } & \multirow[b]{2}{*}{$P$ values } \\
\hline & Mean & SD & Mean & SD & Mean & SE & \\
\hline \multicolumn{8}{|c|}{ Total serum cholesterol (mmol/l) } \\
\hline Intervention group & 4.91 & 0.81 & 4.56 & 0.77 & -0.27 & 0.04 & \multirow[t]{2}{*}{ NS } \\
\hline Control group & 4.49 & 0.76 & 4.49 & 0.79 & -0.12 & 0.04 & \\
\hline \multicolumn{8}{|l|}{$\mathrm{LDL}(\mathrm{mmol} / \mathrm{l})$} \\
\hline Intervention group & 3.07 & 0.74 & $2 \cdot 70$ & 0.73 & -0.30 & 0.04 & \multirow[t]{2}{*}{$<0.001$} \\
\hline $\begin{array}{l}\text { Control group } \\
\mathrm{HDL}(\mathrm{mmol} / \mathrm{l})\end{array}$ & $2 \cdot 68$ & 0.72 & $2 \cdot 70$ & 0.69 & -0.08 & 0.04 & \\
\hline Intervention group & 1.56 & 0.33 & 1.50 & 0.39 & -0.04 & 0.02 & \multirow[t]{2}{*}{ NS } \\
\hline Control group & 1.52 & 0.38 & 1.42 & 0.38 & -0.14 & 0.02 & \\
\hline \multicolumn{8}{|l|}{ Total cholesterol:HDL } \\
\hline Intervention group & 3.27 & 0.87 & $3 \cdot 20$ & 1.07 & -0.07 & 0.05 & \multirow[t]{2}{*}{$<0.05$} \\
\hline Control group & $3 \cdot 12$ & 0.87 & 3.33 & 0.90 & 0.24 & 0.06 & \\
\hline \multicolumn{8}{|l|}{ LDL:HDL } \\
\hline Intervention group & 2.08 & 0.79 & 1.94 & 0.93 & -0.13 & 0.05 & \multirow[t]{2}{*}{$<0.001$} \\
\hline Control group & 1.91 & 0.77 & 2.04 & 0.77 & 0.14 & 0.05 & \\
\hline \multicolumn{8}{|c|}{ Triacylglycerols (mmol/l) } \\
\hline Intervention group & 0.62 & 0.28 & 0.79 & 0.33 & 0.16 & 0.02 & \multirow[t]{2}{*}{ NS } \\
\hline Control group & 0.63 & 0.28 & 0.81 & 0.31 & 0.20 & 0.02 & \\
\hline
\end{tabular}

* The difference between the two groups was estimated with a general linear model (GLM) adjusted for baseline values, sex, initial BMI, change in height and parental education. School was taken as a random effect. Summaries are presented for those pupils with biochemical data in both 1992 and 1998. For details of procedures, see p. 316.

IG and CG being $-130 \cdot 2$ to $-46 \cdot 4 \mathrm{~g} / \mathrm{d})$. The significant differences observed for the nutrient intakes might be the cumulative outcome of the small changes observed for each one of the single food groups. For example, at baseline and follow up for IG and CG respectively the daily consumption of meat was $70 \cdot 1$ v. $100 \cdot 5 \mathrm{~g}$ and $73.4 v$. $108.5 \mathrm{~g}$, the daily consumption of fats added to the food 9.2 v. $8.5 \mathrm{~g}$ and 9.6 v. $13.5 \mathrm{~g}$, daily consumption of sugars (sugary snacks and sugar added in milk and fresh fruit juices) was 48.0 v. $22.1 \mathrm{~g}$ and 43.8 v. $39.7 \mathrm{~g}$, vegetables 156.3 v. $188.9 \mathrm{~g}$ and 148.6 v. $182 \mathrm{~g}$ and fruits $112.8 v$. $95.9 \mathrm{~g}$ and $112.6 \mathrm{v} .118 .3 \mathrm{~g}$.

The fitness indices and the time spent in MVPA out of school over the intervention period are presented in Table 3. In the endurance run test a mean increase of 2.5 (SE 0.1) stages in the IG and 1.2 (SE 0.1) stages in the CG was observed $(P<0 \cdot 0001)$. Regarding changes in time spent in MVPA, IG pupils displayed a significantly greater increase in time spent in MVPA over the 6-year period, as compared with the CG (adjusted mean increases of 281.3 (SE 22.0) v. 174.5 (SE 25.7) min/week, $P<0.05$ ).

With regard to the anthropometric data (Table 4), significant differences between IG and CG were found in weight, height, BMI, biceps skinfold and triceps skinfold. Children from the IG were found to have had a significantly higher average gain in height over the 6-year period compared with the CG pupils (adjusted mean gains were 313 (SE 2.6) $\mathrm{mm}$ for the IG and 274 (SE 0.26) $\mathrm{mm}$ for the controls, $P<0 \cdot 001)$. The opposite was noted in weight gain with mean increases of 21.6 (SE 0.37 ) $\mathrm{kg}$ and 22.9 (SE 0.38) $\mathrm{kg}$ in the IG and CG respectively. CG pupils had a significantly higher change in mean BMI (adjusted mean gain $4.28(\mathrm{SE} 0.16)$ v. $\left.3.68(\mathrm{SE} 0.16) \mathrm{kg} / \mathrm{m}^{2}, P<0.05\right)$ and both biceps and triceps skinfold (biceps adjusted mean changes 4.47 (SE 0.24) v. 2.97 (SE 0.24) mm, $P<0.001$ and triceps adjusted mean changes $7.90(\operatorname{SE~} 0.39) v .6 .46(\operatorname{SE~} 0.38) \mathrm{mm}$, $P<0.05)$ than IG pupils, when adjusting for the change in height, sex, parental educational group and baseline values. The percentages of children characterised as overweight and obese (using cut-offs provided by Cole et al. 2000) were similar in each group. At baseline, the percentages were $22 \%$ and $7.3 \%$ for the IG and $24 \%$ and $7.7 \%$ for the CG. At follow up, the percentages were $31 \%$ and $7 \%$ for IG and $34 \%$ and $8.4 \%$ the CG respectively.

Table 5 presents the changes in serum lipid measurements over the intervention period. Significant differences between the two groups in the changes over the 6-year period were found in the LDL concentrations $(P<0.001)$, TC:HDL $(P<0.05)$ and LDL:HDL $(P<0.001)$; all the indices decreasing to a higher extent in the IG, whilst controlling for possible baseline differences. It was found that for both ratios, there was a decrease, on average, in the IG whilst they increased in the CG over the 6-year period (even following adjustment for baseline values and other covariates). No significant differences in the 6-year changes in concentrations between the two groups were noted for the other serum lipids.

In order to examine the available information regarding the county component of variance, changes were examined for each of the two intervention counties separately. There were very few measurements that differed significantly between the two counties, the only notable difference being the TC levels, which decreased to a significantly higher extent in Iraklio compared with Rethimno $(-0.54$ (SE 0.68) v. -0.06 (SE 0.57) $\mathrm{mmol} / \mathrm{l}$ respectively, $P<0 \cdot 001)$. 


\section{Discussion}

To a certain extent, the positive outcomes of the 6-year intervention programme were in accord with the 3-year interim assessment (Manios et al. 1998a, 1999b). The significantly better serum lipid and physical activity values in the IG found both at mid-term and final assessment imply that the intervention programme did influence children's behaviour in relation to health issues. Small-scale changes in serum lipid, and even smaller in obesity indices, have been observed in programmes similar to the present one (Walter et al. 1985, 1988; Tell \& Vellar, 1987; Arbeit et al. 1992). In the 'Know Your Body' programme, on fourth through to eighth grade pupils, modest changes in TC were observed after 1 (Walter et al. 1985) and 5 years of intervention (Walter et al. 1988). In the 'Heart Smart Program', on fourth and fifth grade pupils, only a modest increase in the IG HDL values was observed (Arbeit et al. 1992), while a $4 \%$ reduction in the IG TC was found in the Oslo Youth Study (Tell \& Vellar, 1987) on 10- to 14-year-old pupils after 2 years of intervention. Changes in TC and LDL of higher magnitude were observed in the US DISC study among 8- to 10-year-old children with elevated LDL values at baseline. After 3 years of intensive intervention significant changes in favour of the IG were observed for these biochemical indices while no significant changes were observed in obesity indices (The Writing Group for the DISC Collaborative Research Group, 1995).

The favourable changes, in biochemical and anthropometric indices, observed for the IG in the present study could be attributed to the dietary and exercising changes achieved from this group over the 6-year period. Although the mid-term examination did not provide evidence of difference between the two groups with respect to their nutrient intakes (Manios et al. 1999b), the final outcomes showed significant differences for the most of the dietary variables. Similar changes to ours have also been observed in other studies (The Writing Group for the DISC Collaborative Research Group, 1995; Lytle et al. 1996). The comparatively smaller increase in energy and saturated fat intake in the IG compared with the CG indicates that these changes may have contributed to the positive weight and obesity indices effects. Furthermore, these differences in fat intake between the IG and CG could perhaps be attributed to differences between the two groups regarding the consumption primarily of meat and fats and to a lesser extent other food groups which also contribute to the overall fat intake. Overall these changes seem to be the outcome of the 6 years intervention in which the dietary component primarily focused on the importance of low consumption of meats, fatty snacks and fats in general and use of olive oil in moderation. Traditionally olive oil contributes the vast majority of fats in the Cretan diet (Kafatos et al. 1991; Kafatos \& Papoutsakis, 1998). On the other hand, less emphasis was placed through the intervention programme on the increased consumption of fruits and vegetables, which was probably considered for granted as part of the diet. This could be considered a limitation of the present study, possibly responsible for the somewhat less favourable profile of vegetables and fruits consumption in the IG and consequently the less favourable consumption of fibre from the IG.

Regarding leisure time physical activity, the significantly higher increase in time devoted to MVPA by the IG concurs with the findings of the CATCH study (McKenzie et al. 1996). This finding should probably be attributed to out-of-school encouragement, reflecting changes in parental attitudes in the IG. The observed increased time devoted to MVPA by the IG pupils at the end of the intervention period is due to both an increased time devoted to outdoor activities in the neighbourhood but also in organised club activities, primarily team sports. Furthermore, in the present study the pupils in the IG achieved higher improvements in the endurance run test, compared with the controls. This is possibly an outcome of the higher levels of leisure time physical activity and re-organisation of the PE classes to facilitate the needs of the health and nutrition programme (Manios et al. 1998a). A similar tendency in fitness performance, without reaching a significant level, was observed in the CATCH study (McKenzie et al. 1996).

The positive results of the present study could be attributed to both the high prevalence of chronic disease risk factors and behavioural risk factors at baseline (Manios et al. $1998 b, 1999 a, b)$. This situation left room for significant improvements and increased the likelihood of positive changes after the intervention's implementation (Lionis et al. 1991). The baseline data are indicative of the dramatic deviation of the dietary habits of children from the traditional Cretan diet, which have occurred over the last few decades (Voukiklaris et al. 1996; Mamalakis \& Kafatos, 1996). The findings of other health education programmes applied to pupils from low and middle socio-economic backgrounds (Arbeit et al. 1992), pupils with elevated serum cholesterol (Resnicow et al. 1989; The Writing Group for the DISC Collaborative Research Group, 1995), or at least one (Harrell et al. 1999) or two (Harrell et al. 1998) cardiovascular disease risk factors, are similar to ours. On the other hand, other intervention programmes reported difficulties in achieving positive changes in similar health indices in this age group (Nader et al. 1989; Luepker et al. 1996; Webber et al. 1996), something which could partially be attributed to the small variations between subjects in physiological and behavioural variables but also the age-dependent increase reported in the physiological variables (Berenson \& Epstein, 1983; Lauer et al. 1988).

The second parameter possibly contributing to the changes observed in the present study is the high degree of parental participation and the applied school-based intervention scheme. There is ample evidence that family and parental involvement in health education programmes is associated with significant gains in both behavioural and physiological indices (Walter et al. 1985; Bush et al. 1989; Tamir et al. 1990; Resnicow et al. 1992; The Writing Group for the DISC Collaborative Research Group, 1995; Perry et al. 1998). On the other hand, school-based programmes with limited or no parental participation have failed to reach such significant gains (Donnelly et al. 1996; Harrell et al. 1996; Nader et al. 1996; Webber et al. 1996; Smolak et al. 1998). 
A third explanation for the pronounced positive changes observed may been related to the intervention scheme used in the present study, in which the health education programme was combined with PE classes, allowing more intervention hours. In particular the number of school hours devoted annually to intervention exceeded the suggested 40-50 h cut off for efficient health behaviour changes (Contento et al. 1992). Unlike CATCH (McKenzie et al. 1996) and CHIC (Harrell et al. 1996), the primary goal of the intervention, although concentrated more on aerobic forms of health-related exercises, was not to gain substantial increases in the time devoted in MVPA during PE classes. Instead the focus of the present study was on children's enjoyment and willingness to participate in the PE classes. For this reason emphasis was placed on total class participation in pleasant, non-competitive forms of exercise (Manios et al. 1998a). This strategy, combined with parental encouragement to support their children in increasing their physical activity out of school, has been proven most effective in fostering activity independence in children (Manios et al. 1998b). Consequently, emphasis was given to the time devoted to MVPA outside the school as an indicator of effectiveness of the programme both for the children involved and their parents. Hence, the significant increase in leisure time MVPA in the IG is an indicator of the intervention's effectiveness on parental attitudes and on intrinsic incentives for increased physical activity and fitness.

Finally, among the parameters explaining the magnitude of the changes observed should be included the relatively long duration of intervention and teachers' compliance delivering the programme (Manios et al. 1999b). Similar to the present study, the relationship between the duration of intervention and the magnitude of the changes observed have clearly been demonstrated in the 'Know Your Body' programme (Walter et al. 1985, 1988).

A shortcoming of the present study was that after the educational seminars, which took place at the start of each academic year, there was some, but not very close, supervision of the educationalists involved. Therefore, the application of the taught component of the intervention programme, regarding health issues, which required the active participation of small groups of pupils in relation to various activities both within and outside the school, depended entirely on the interest of the educationalists. There was no assessment of the knowledge, preparation, interest or teaching ability of the staff involved or the way in which small work groups were organised and how imaginative teachers were in devising innovative and attractive methods which could subsequently influence pupils to make better choices with regard to health issues. In the present study, the intervention was assessed with a kind of 'black box' approach in that although differing levels of all random components were accounted for in the models used (by incorporation of the random school effect), there can be no quantitative estimation of the extent of teacher influence on the subsequent choices made by the pupils. We are trying to overcome this shortcoming in studies currently being undertaken in which we try to examine whether any changes in the behaviour of pupils are related to the motivation and degree of interest of the educationalists involved. The costs of this undertaking, however, both in terms of finance and required time, are high, the study data are limited and the objections of the idea of assessment by many educationalists are a barrier yet to be overcome. Potential threats to the validity of the study may exist although, as far as we know, there were no major factors that may have differed between the intervention and control groups that were not accounted for in the statistical analysis.

Despite the study's shortcomings, its findings underline the importance of such programmes in health promotion and disease prevention and are in line with the findings of other similar studies focusing on developing certain changes in the school environment in order to help pupils develop and maintain lifelong healthy habits (Wechsler et al. 2000). Combining the health education programme with the PE classes optimises both the physical activity and fitness as well as the nutritional and health-promotion components of the programme, thus allowing more hours of intervention with the least possible time restriction on the remainder of the curriculum. Although the long-term effects of our programme can only be found by tracking this population through to adolescence and finally adulthood, our findings indicate that programmes such as ours are likely to be of substantial importance for future public health.

\section{Acknowledgements}

The study was funded by Kellogg's, the Greek Ministry of Sports and the Greek Ministry of Education. We would also like to acknowledge the help of our colleagues: Sofia Flouri, Eva Mpalomenaki, Eva Mouka, Ioanna Apostolaki, Eleni Kantidaki, Fotini Hiladaki, Caroline Codrington, Dimitris Athanasopoulos, Xenofontas Manias, Hara Galanaki, Xrisoula Perdikogianni, Manolis Linardakis, Irini Markatji, Maria Hourdaki and Yannis Mitakis. We would also like to thank Bishop Ireneos of Kydonias and Apokoronau for the kind hospitality offered to our reseasrch team in Hania.

\section{References}

Aravanis C, Mensink RP, Karalias N, Christodoulou B, Kafatos A \& Katan M (1988) Serum lipids, apoproteins and nutrient intake in rural Cretan boys consuming high-olive-oil diets. Journal of Clinical Epidemiology 41, 1117-1123.

Arbeit ML, Johnson CC, Mott SD, Harsha DW, Nicklas TA, Webber LS \& Berenson GS (1992) The Heart Smart Cardiovascular School Health Promotion: Behaviour Correlates of Risk Factor Change. Preventive Medicine 21, 18-32.

Berenson GS \& Epstein FH (1983) Conference on blood lipids in children: Optimal levels for early prevention of coronary artery disease. Preventive Medicine 12, 741-797.

Bush PJ, Zuckerman AE, Taggart VS, Theiss PK, Peleg EO \& Smith SA (1989) Cardiovascular risk factor prevention in black school children: the "Know Your Body" evaluation project. Preventive Medicine 16, 215-227.

Cole JM, Bellizzi MC, Flegal KM \& Dietz WH (2000) Establishing a standard definition for child overweight and obesity worldwide: international survey. British Medical Journal 320, $1240-1245$. 
Committee of Experts on Sports Research (1988) EUROFIT. Rome: Edigraf Editoriale Grafica.

Contento IR, Manning AD \& Shannon B (1992) Research Perspective on School-based Nutrition Education. Journal of Nutrition Education 24, 247-260.

Donnelly JE, Jacobsen DJ, Whatley JE, Hill JO, Swift LL, Cherrington A, Polk B, Tran ZV \& Reed G (1996) Nutrition and physical activity program to attenuate obesity and promote physical and metabolic fitness in elementary school children. Obesity Research 4, 229-243.

Fordyce MK, Christakis G, Kafatos A, Duncan R \& Cassady J (1983) Adipose tissue fatty acid composition of adolescents in a US-Greece cross-cultural study of coronary heart disease risk factors. Journal of Chronic Diseases 36, 481-486.

Friedewald W, Levy RI \& Fredrikson DS (1972) Estimation of the concentration of low density lipoprotein cholesterol in plasma without use of the preparative ultracentrifuge. Clinical Chemistry 18, 499-502.

GNSC (1995) Statistic Data on the Greek Population. Athens: Greek National Statistic Committee.

Harrell JS, Gansky SA, McMurray RG, Bangdiwala SI, Frauman AC \& Bradley CB (1998) School-based interventions improve heart health in children with multiple cardiovascular disease risk factors. Pediatrics 102, 371-380.

Harrell JS, McMurray RG, Bangdiwala SI, Frauman AC, Gansky SA \& Bradley CB (1996) Effects of school-based intervention to reduce cardiovascular disease risk factors in elementaryschool children: The Cardiovascular Health in Children (CHIC) Study. Journal of Pediatrics 128, 797-805.

Harrell JS, McMurray RG, Gansky SA, Bangdiwala SI \& Bradley CB (1999) A public health vs a risk-based intervention to improve cardiovascular health in elementary school children: the Cardiovascular Health in Children Study. American Journal of Public Health 89, 1529-1535.

Jacobs DR, Luepker RV, Mittelmark MB, Folsom AR, Pirie PL, Mascioli SR, Hannan PJ, Pechacek TF, Bracht NF, Carlaw RW, Kline FG \& Blackburn $\mathrm{H}$ for the Minnesota Heart Health Program Research Group (1986) Community-wide prevention strategies: Evaluation design of the Minnesota Heart Health Program. Journal of Chronic Diseases 39, 777-788.

Kafatos A, Kouroumalis I, Vlachonikolis I, Theodorou C \& Labadarios D (1991) Coronary-heart-disease risk factor status of the Cretan urban population in the 1980s. American Journal of Clinical Nutrition 54, 591-598.

Kafatos A \& Mamalakis G (1993) Policies and programs in nutrition and physical fitness in Greece. In Nutrition and Fitness in Health and Disease, pp. 206-217 [AP Simopoulos, editor]. Basel: Karger.

Kafatos A, Manios Y, Markatji I, Giachetti I, Vaz de Almeida MD \& Engstrom LM (1999) Regional, demographic and national influences on attitudes and beliefs with regard to physical activity, body weight and health in a nationally representative sample in the European Union. Public Health Nutrition 2, 87-89.

Kafatos A, Panagiotakopoulos G, Bastakis N, Trakas D, Stoikidou M \& Pantelakis S (1981) Cardiovascular risk factor status of Greek adolescents in Athens. Preventive Medicine 10, $173-186$.

Kafatos A \& Papoutsakis G (1998) Mortality rates in Greece and their relationship to the Mediterranean diet and to health and nutrition education. Iatriki 73, 287-301.

Lauer RM, Lee J \& Clarke WR (1988) Factors affecting the relationship between childhood and adult cholesterol levels: The Muscatine study. Pediatrics 82, 309-318.

Lionis C, Kafatos A, Vlachonikolis J, Vakaki M, Tzortzi M \& Petraki A (1991) The effects of a Health Education Intervention
Program among Cretan Adolescents. Preventive Medicine 20, 685-699.

Luepker RV, Perry CL, McKinlay SM, Nader PR, Parcel GS, Stone EJ, Webber LS, Elder JP, Feldman HA \& Johnson CC (1996) Outcomes of a Field Trial to Improve Children's Dietary Patterns and Physical Activity. A child and adolescent trial for cardiovascular health (CATCH). Journal of the American Medical Association 275, 768-776.

Lytle LA, Stone EJ, Nichaman MZ, Perry CL, Montgomery DH, Nicklas TA, Zive MM, Mitchell P, Dwyer JT, Ebzery MK, Evans MA \& Galati TP (1996) Changes in Nutrient Intakes of Elementary School Children Following a School-based Intervention: Results from the $\mathrm{CATCH}$ Study. Preventive Medicine 25, 465-477.

McKenzie TL, Nader PR, Stikmiller PK, Yang M, Stone EJ, Perry CL, Taylor WC, Epping JN, Feldman HA, Luepker RV \& Kelder SH (1996) School physical education: Effect of a Child and Adolescent Trial for Cardiovascular Health. Preventive Medicine 25, 423-431.

Mamalakis G \& Kafatos A (1996) Prevalence of obesity in Greece. International Journal of Obesity 20, 488-492.

Manios Y, Kafatos A \& Codrington C (1999a) Gender differences in physical activity and fitness in young children in Crete. Journal of Sports Medicine and Physical Fitness 39, 24-30.

Manios Y, Kafatos A \& Mamalakis G (1998a) The effects of a health education intervention initiated at first grade over a 3 year period: physical activity and fitness indices. Health Education Research 13, 593-606.

Manios Y, Kafatos A \& Markakis G (1998b) Physical activity of 6 year old children: Validation of two proxy reports. Pediatric Exercise Science 10, 176-188.

Manios Y, Moschandreas J, Hatzis C \& Kafatos A (1999b) Evaluation of a health and nutrition intervention in primary school children of Crete over a three-year period. Preventive Medicine 2, 149-159.

Nader PR, Sallis JF, Patterson TL, Abramson IS, Rupp JW, Senn KL, Atkins CJ, Roppe BE, Morris JA \& Wallace JP (1989) A family approach to cardiovascular risk reduction: results from the San Diego Family Health Project. Health Education Quarterly 15, 57-74.

Nader PR, Sellers DE, Johnson CC, Perry CL, Stone EJ, Cook KC, Bebchuk J \& Luepker RV (1996) The effect of adult participation in a school-based family intervention to improve children's diet and physical activity: The Child and Adolescent Trial for Cardiovascular Health. Preventive Medicine 25, 455-464.

Perry CL, Bishop DB, Taylor G, Murray DM, Mays RW, Dudovitz BS, Smyth M \& Story M (1998) Changing fruit and vegetable consumption among children: The 5-a-day power plus program in St. Paul, Minnesota. American Journal of Public Health 88, 603-609.

Resnicow K, Cohn L, Reinhardt J, Cross D, Futterman R, Kirschner E, Wynder EL \& Allegrante JP (1992) A three-year evaluation of the know your body program in inner-city schoolchildren. Health Education Quarterly 19, 463-480.

Resnicow K, Orlandi MA, Vaccaro D \& Wynder E (1989) Implementation of a pilot school-site cholesterol reduction intervention. Journal of School Health 59, 74-78.

Smolak L, Levine MP \& Schermer F (1998) A controlled evaluation of an elementary school primary prevention program for eating problems. Journal of Psychosomatic Research 44, 339-353.

Tamir D, Feurstein A, Brunner S, Halfon S, Reshef A \& Palti H (1990) Primary Prevention of Cardiovascular Disease in Childhood: Changes in Serum Total Cholesterol: High Density Lipoprotein and Body Mass Index after 2 years of Intervention 
in Jerusalem Schoolchildren Age 7-9 years. Preventive Medicine 19, 22-30.

Tell G \& Vellar O (1987) Noncommunical disease risk factor intervention in Norwegian adolescents: The Oslo youth study. In Cardiovascular Risk Factors in Childhood: Epidemiology and Prevention, pp. 203-217 [B Hetzel and G Berenson, editors]. Amsterdam: Elsevier.

The Writing Group for the DISC Collaborative Research Group (1995) Efficacy and Safety of Lowering dietary intake of fat and cholesterol in children with elevated low-density lipoprotein cholesterol. Journal of the American Medical Association 273, 1429-1435.

US Department of Agriculture (2001) USDA Nutrient Database for Standard Reference. Release 14, Agricultural Research Service. (Nutritional Data Laboratory Home page; http:// www.nal.usda.gov/fnic/foodcomp).

Voukiklaris GE, Kafatos A \& Dontas A (1996) Changing prevalence of coronary heart disease risk factors and cardiovascular diseases in men of a rural area of Crete from 1960 to 1991. Angiology 47, 43-49.

Walter HJ, Hofman A, Connelly PA, Barrett LT \& Kost KL (1985) Primary prevention of chronic disease in childhood: Changes in risk factors after one year of intervention. American Journal of Epidemiology 122, 772-781.
Walter HJ, Hofman A, Vaughan RD \& Wynder EL (1988) Modification of risk factors for coronary heart disease: five-year results of the school-based intervention trial. New England Journal of Medicine 318, 1093-1100.

Walter HJ \& Wynder EL (1989) The Development, Implementation, Evaluation and Future Directions of a Chronic Disease Prevention Programme for Children: The "Know Your Body" Study. Preventive Medicine 18, 59-71.

Webber LS, Osganian SK, Feldman HA, Wu M, McKenzie TL, Nichaman M, Lytle LA, Edmundson E, Cutler J, Nader PR \& Luepker RV (1996) Cardiovascular risk factors among children after a 2 1/2-year intervention - The CATCH study. Preventive Medicine 25, 432-441.

Wechsler H, Deveraux RS, Davis M \& Collins J (2000) Using the school environment to promote physical activity and healthy eating. Preventive Medicine 31, S121-S137.

Williams C, Arnold C \& Wynder E (1977) Primary Prevention of Chronic Disease Beginning in Childhood. The "Know Your Body" programme: Design of the study. Preventive Medicine 6, 344-357.

Wynder EL, Williams CL, Laakso K \& Levenstein M (1981) Screening for chronic disease in children from fifteen countries. Preventive Medicine 10, 121-132. 